\title{
Detection of methicillin-resistant Staphylococcus aureus in broiler and broilers farm works in Duhok, Iraq by using conventional and PCR techniques
}

\author{
M.S. Assafi ${ }^{1}$, H.A. Hado ${ }^{2}$ and I.S. Abdulrahman ${ }^{3}$ \\ ${ }^{1}$ Department of Biology, School of Sciences, University of Duhok, Duhok, ${ }^{2}$ Department of Biology, Faculty of Sciences, \\ University of Zakho, Zakho, ${ }^{3}$ Department of Pharmaceutic, College of Pharmacy, University of Duhok, Duhok, Iraq \\ Email: ${ }^{1}$ mahde.assafi@uod.ac, ${ }^{2}$ hishiyar.akre@gmail.com, ${ }^{3}$ ibtesam.abdulrhman@uod.ac
}

(Received January 18, 2019; Accepted March 26, 2019)

\begin{abstract}
Livestock-associated methicillin-resistant Staphylococcus aureus (MRSA) has become a global public health concern. The purpose of this study was to investigate the prevalence rates of MRSA infection amongst broiler chickens and broilers farm workers. The total samples used in this study were 306. Cloacal swab samples from 231 broilers and nasal swab samples from 75 broilers farm workers were collected from five farms in Duhok city, Iraq. Isolation and identification of MRSA isolates were carried out and the antibiotic susceptibility were screened. Molecular characterization of all isolates was performed by using polymerase chain reaction (PCR) technique to detect the mecA gene. S. aureus was detected among $84 \%(63 / 75)$ of the farms workers samples and among $84.8 \%(196 / 231)$ of the broiler's samples. The $S$. aureus isolated from farm workers and broilers appeared resistant to oxacillin $28.6 \%(18 / 63)$, and $32.1 \%(63 / 196)$, respectively. MRSA colonization in farm workers and broilers was $24 \%(18 / 75)$ and $27.3 \%$ (63/231) respectively. The $S$. aureus isolates showed the most resistant to chloramphenicol and the least resistant to vancomycin. The results of the PCR assays revealed that $85.7 \%(12 / 14)$ of $S$. aureus isolates from farm workers and $44.4 \%(16 / 36)$ of $S$. aureus isolates from broilers were positive for the mecA gene. The direct handling of broilers by farm workers plays the important role for transport the MRSA isolates from broilers to broilers farm workers.
\end{abstract}

Keywords: MRSA, S. aureus; mecA gene; Broilers; Farm workers

Available online at http://www.vetmedmosul.com, (C) 2020, College of Veterinary Medicine, University of Mosul.

This is an open access article under the CC BY 4.0 license (http://creativecommons.org/licenses/by/4.0/).

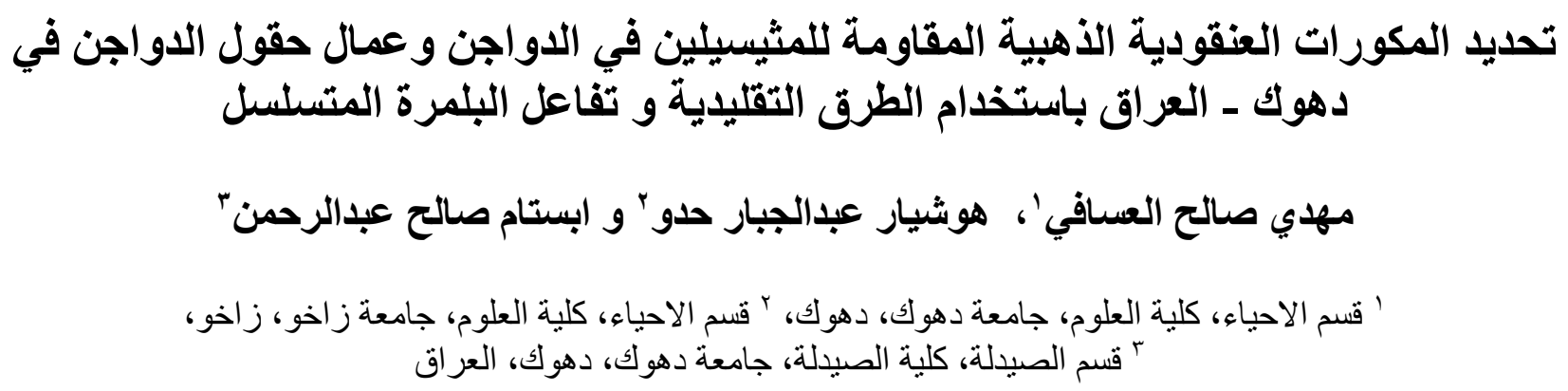

الخلاصة

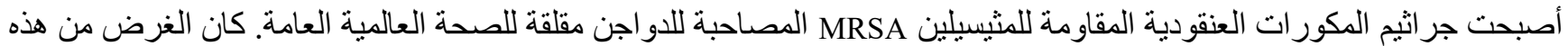

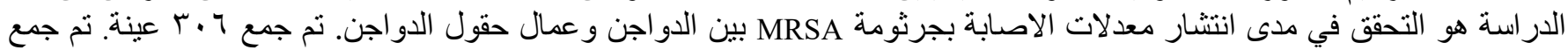

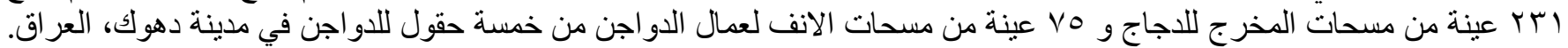

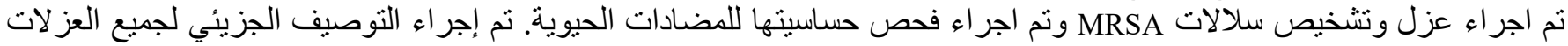
بو اسطة تفاعل البلمرة المتسلسل للكثف عن الجين. 


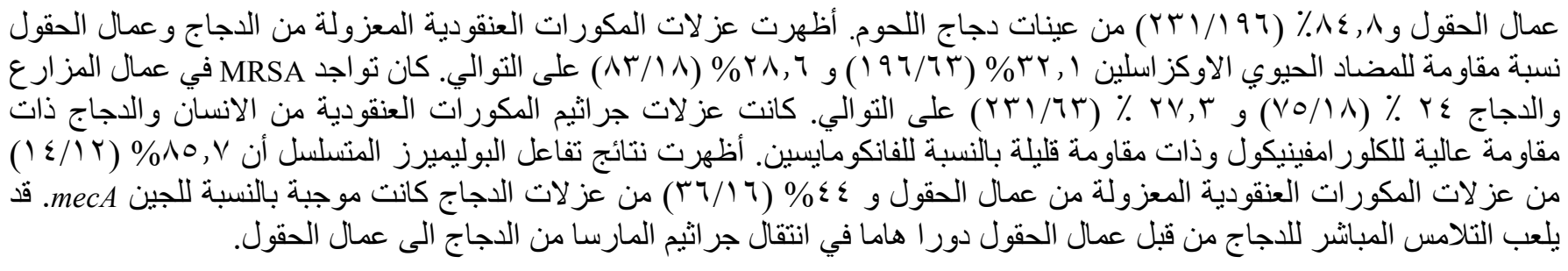

\section{Introduction}

Staphylococcus aureus (S. aureus) is an opportunistic pathogen capable of causing severe disease to farm workers and domesticated animals (1). S. aureus has ability to acquire resistance to several types of antibiotics. In the early 1940s, the concept of resistance of $S$. aureus isolates to antibiotic therapy was raised, and the prevalence of the antibiotic resistance has dramatically increased in recent decades due to misuse used of antibiotics and the prescription that, used for therapeutics of diseases (2). Since 1959, penicillin-resistant $S$. aureus infections have been successfully treated with methicillin. However, in 1961, there were several of the reports from the United Kingdom showed that $S$. aureus isolates had appeared acquired resistance to the methicillin and this was first identification of the methicillin-resistant $S$. aureus strains (3).

The MRSA infection was first subdivided into hospitalassociated (HA-MRSA) and community-associated MRSA (CA-MRSA) infections. In addition, a third group has been emerged and known as livestock-associated MRSA (LAMRSA) (4-6). S. aureus isolated from poultry has become a serious zoonotic risk factor on a global scale for the farm workers groups who handle or live in close proximity to chickens (1). The infection with LA-MRSA has been globally documented $(2,3)$. At present, MRSA strains have been identified by using the biochemical test to detect the phenotypical characterization of MRSA which appeared resistance to all the antibiotics that have been manufactured to date $(4,5)$. The mecA gene, a (associated with resistance in MRSA) encodes the altered penicillin binding protein $(\mathrm{PBPa})$, which has a low affinity for $\beta$-lactam group antibiotics and prevent it to link with $\beta$-lactams. The aims of this study were to investigate the prevalence of $S$. aureus and MRSA among broiler chickens and broilers farm workers. In addition, to assess the presence of the mecA gene in MRSA isolates using PCR in different farms in Duhok governorate, Iraq.

\section{Materials and methods}

\section{Study design and sampling}

A total of 306 swab samples were collected, 231 samples from broiler chickens and 75 samples from farm workers were included (Table 2). The study was conducted from December 2016 to October 2017. The study was based on voluntary participation. The samples were collected in a randomly selected from 12 rural poultry farms from all districts in Duhok city. The farms subdivided into five groups according to their location in different districts in Duhok governorate (Akre, Amedi, Bardarash,shekan and Zakho) (Table 2). The farm workers nasal samples were obtained by inserting a sterile swab 2 $\mathrm{cm}$ into the nostril and gently rotated against the mucosal surface for approximately 5-10 second. The broilers samples were obtained by inserting a sterile swab stick in the cloaca and gently rubbing, the swab against the mucosal surface for approximately 5-10 second. The farm workers and broilers samples were transport into $10 \mathrm{ml}$ trypticase soy broth containing $70 \mathrm{mg} / \mathrm{ml} \mathrm{NaCl}$ and incubated at $37^{\circ} \mathrm{C}$ for $24 \mathrm{hrs}$.

\section{Cultural, biochemical and molecular identification of $S$. aureus and MRSA}

A loopful of the inoculum from the enrichment broth was streaked on the mannitol-salt agar and incubated at $37^{\circ} \mathrm{C}$ for $24 \mathrm{hrs}$. The suspected $S$. aureus colonies were selected and sub-cultured on the mannitol-salt agar to obtain a pure culture. The presumptive colonies of $S$. aureus were further identified microscopically and biochemical tests. The strains were considered as $S$. aureus relying on mannitol salt agar fermentation, gram stain, morphology, catalase test and coagulase test. MRSA isolates were identified upon their resistance to an oxacillin $6 \mu \mathrm{l} / \mathrm{ml}$ using agar screening method (6). MRSA isolates were further identified based on the presence of the mecA gene using PCR-based screening method.

\section{Extraction of chromosomal DNA and polymerase chain reaction (PCR)}

The DNA of the $S$. aureus isolates was extracted by using commercial DNA isolation kit according to manufacturer instructions (AccuVis Bio, UAE). The purity and concentration of DNA of each isolate was measured by using Nanodrop device (Thermo scientific-USA). The PCR technique was used to screen the existence of the mecA gene in MRSA isolates utilising two previously described primers, MR1 forward (5'GTGGAATTGGCCAATACAG G3') and MR2 reverse primer (5'TGAGTTCTGCAGTACC 
GGAT3') (7, 8). The reactions were achieved using a PCR Thermocycler (Applied biosystem, USA). Reactions were performed in a $20 \mu \mathrm{l}$ final volume containing $10 \mu \mathrm{l}$ of master mix, $2 \mu \mathrm{l} S$. aureus genomic DNA (final concentration 50-100 ng/ $\mu 1), 1 \mu 1$ of each primer MR1 and MR2 at final concentration $5 \mu \mathrm{M}$, and $6 \mu \mathrm{l}$ of distilled water. Amplification conditions were: denaturation at $95^{\circ} \mathrm{C}$ for the $30 \mathrm{~s}$, annealing at $55^{\circ} \mathrm{C}$ for $1 \mathrm{~min}$, extension at $72^{\circ} \mathrm{C}$, denaturation for $1 \mathrm{~min}$ at $95{ }^{\circ} \mathrm{C}$, (for 33 cycles), and a final extension for $5 \mathrm{~min}$ at $72^{\circ} \mathrm{C}(9)$. PCR products (bands) were visualized after gel electrophoresis at $100 \mathrm{~V}$ in a $1.5 \%$ agarose gels using UV Transilluminator (Cleaver scientific, $\mathrm{UK})$.

\section{Antibiotic sensitivity test}

The agar screening method was used to investigate the antibiotic susceptibility according to the Clinical Laboratory Standards Institute (CLSI) recommendations (6). The nine different antibiotics from different antimicrobial groups were used in this study that supplied by Bioanalyse (Turkey) (Table 1). A single colony was selected from an overnight culture and inoculated into $5 \mathrm{ml}$ of brain heart infusion broth and then incubated at $37^{\circ} \mathrm{C}$ overnight. The desired antibiotic with final concentration was prepared on Muller Hinton agar or brain heart infusion (BHI) agar (Oxoid, England). Bacterial suspension was tested to obtain a density of $0.5 \mathrm{McF}$ arland turbidity then 10 $\mu \mathrm{L}$ drop was spotted onto agar plate surface and were incubated at $35^{\circ} \mathrm{C}$ overnight. The vancomycin resistance was defined as the capability of growth in BHI agar screening media (6 $\mu \mathrm{g} / \mathrm{ml}$ vancomycin). Growth was considered as a positive result and the isolates were further investigated (MIC $\geq 16 \mu \mathrm{g} / \mathrm{ml}$ ) to confirm the identifications according to CLSI recommendations.

\section{Ethics statement}

Informed written consent was obtained from farm workers. The study was conducted with the approval of ethics committee in the University of Zakho, Faculty of Sciences, Iraq.

\section{Data analysis}

Chi-squared test was used to assess the associations between variables. All statistical analysis was performed using the SPSS 18 software. $\mathrm{P}<0.05$ were considered as significant.

Table 1: Antimicrobial agents used in the current study

\begin{tabular}{lcc}
\hline Antibiotic group & Antibiotic & $\mu \mathrm{g} / \mathrm{ml}$ \\
\hline Beta-Lactams (Penicillins) & Oxacillin (OXA) & 6 \\
Glycopeptides & Vancomycin (VAN) & 6 \\
Phenicoles & Chloramphenicol (CHL) & 32 \\
Quinolones & Ciprofloxacin (CIP) & 4 \\
Macrolides & Tilmicosin (TIL) & 8 \\
Tetracyclines & Doxycyclin (Dox) & 16 \\
Aminoglycosides & Amikacin (AMK) & 64 \\
Beta-Lactams (Carbapenems) & Meropenem (MEM) & 16 \\
Macrolides & Erythromycin (ERY) & 8 \\
\hline
\end{tabular}

\section{Results}

\section{Prevalence of $S$. aureus and MRSA in farm workers and broilers in different farms}

In the current study, the carriage rate of $S$. aureus among broilers in all farms was $84.8 \%(196 / 231)$ whereas it was $84 \%(63 / 75)$ among farm workers. The differences of the incidence rates of $S$. aureus in broilers and broilers farm workers in all farms was statistically non-significant $(p=$ 0.85 ). However, in broilers, there were significant differences of the prevalence of $S$. aureus in different farms $(\mathrm{p}=0.0001)$ and the prevalence ranged from $60 \%$ to $97 \%$ (Table 2).

The $S$. aureus nasal carriage rate among farm workers in different farms was significantly different $(\mathrm{p}=0.02)$. When comparing individual farms, MRSA infection prevalence was as high $100 \%$ to as low as $46 \%$ amongst farm workers (Table 2).

Table 2: Distribution of S. aureus and MRSA isolates among broilers and broilers farm workers in different farms

\begin{tabular}{|c|c|c|c|c|c|c|c|c|}
\hline \multirow{2}{*}{$\begin{array}{l}\text { Farm } \\
\text { groups }\end{array}$} & \multicolumn{4}{|c|}{ S. aureus } & \multicolumn{4}{|c|}{ MRSA } \\
\hline & Broilers & $P$ value & Farm workers & $P$ value & Broilers & $P$ value & Farm workers & $P$ value \\
\hline Akre & $42 / 46(91.3 \%)$ & & $21 / 21(100 \%)$ & & $6 / 46(13 \%)$ & & $1 / 21(4.8 \%)$ & \\
\hline Amediya & $49 / 53(92.5 \%)$ & & $7 / 13(53.8 \%)$ & & $19 / 53(35.8 \%)$ & & $1 / 13(7.7 \%)$ & \\
\hline Bardarash & 18/30 (60\%) & 0.0001 & 8/8 (100\%) & 0.02 & $3 / 30(10 \%)$ & 0.001 & 6/8 (75\%) & 0.0003 \\
\hline $\begin{array}{l}\text { Shekan } \\
\text { Zakho }\end{array}$ & $\begin{array}{l}45 / 59(76.3 \%) \\
42 / 43(97.7 \%)\end{array}$ & & $\begin{array}{c}15 / 17(88.2 \%) \\
12 / 16(75 \%)\end{array}$ & & $\begin{array}{c}25 / 59(42.4 \%) \\
10 / 43(23.3 \%)\end{array}$ & & $\begin{array}{l}7 / 17(41.2 \%) \\
3 / 16(18.8 \%)\end{array}$ & \\
\hline Total & $196 / 231(84.8 \%)$ & & $63 / 75(84 \%)$ & 0.85 & $63 / 231(27.3 \%)$ & & $18 / 75(24 \%)$ & 0.57 \\
\hline
\end{tabular}


S. aureus isolates from farm workers groups and broilers from all farms were screened for resistance to oxacillin. Amongst farm workers groups, 24\% (18/75) of the $S$. aureus isolates where identified as MRSA carrier. While in broilers, $27.3 \%(63 / 231)$ were colonized with MRSA (Table 2). There was a significant difference between the distribution of MRSA among farm workers $(\mathrm{p}=$ $0.0003)$ or broilers $(p=0.001)$ amongst all farms. However, when comparing resistance rate of MRSA isolates in all farms, the occurrence of MRSA was statistically nonsignificant $(\mathrm{p}=0.57)$.

In broilers, the incidence rate of MRSA isolates among farms was statistically different and the carriage rates ranged from $13 \%$ to $42.4 \%$. The carriage rate of MRSA isolates among farm workers was significantly different in different farms (ranged from $5 \%$ to $75 \%$ ). The highest rate (42.4\%) of MRSA among broilers was found in Shekan farms while the highest rate $(75 \%)$ in farm workers was observed in Bardarash farms.

\section{Antibiotic susceptibility of $S$. aureus and MRSA in farm workers and broilers in different farms}

The susceptibility of MRSA isolates from farm workers and broilers against different antibiotics from different farms were variable. Generally, farm workers MRSA isolates showed different patterns of resistance toward antibiotics in comparison to broilers isolates. Amongst the 18 farm workers MRSA isolates. The highest resistant rate of $S$. aureus isolates was against chloramphenicol was $83 \%$ $(15 / 18)$. Moreover, farm workers MRSA resistance was $39 \%$ against dyoxycillin, $28 \%$ to ciprofloxacin, $22 \%$ to amikancin, $11 \%$ to tilmicosin and meropenem, $5.5 \%$ to erythromycin, and $5.5 \%$ to vancomycin. While amongst broilers MRSA, the highest resistant percentage was observed against chloramphenicol 81\% (51/63) followed by ciprofloxacin and dyoxycillin which were $63 \%$ and $49 \%$, respectively. The resistance of MRSA isolates toward meropenem was $57 \%, 43 \%$ to amikancin, $33 \%$ to tilmicosin, $22 \%$ to erythromycin and $3 \%$ to vancomycin. The resistance of broilers and farm workers MRSA isolates was significantly different against ciprofloxacin and meropenem ( $P$ value was 0.023 and 0.003 respectively) (Table 3).

\section{Molecular detection of the mec $A$ gene in MRSA isolates}

The MRSA isolates were identified based on their phenotypic resistance to oxacillin. However, the antibiogram typing (oxacillin-agar screen test) is not able to confirm the presence of the mecA gene. Therefore, PCR was used to screen the existence of the mecA gene in MRSA isolates.

Molecular identification of MRSA strains was performed by detection of the mecA gene in MRSA strains using PCR. 50 MRSA isolates (36 from broilers and 14 from farm workers) from different farms were selected and screened for the mecA gene. The amplified PCR products for the identification of the mecA gene were visualized on the agarose gel and the expected band was observed (1,339 bp) (Figure 1). 56\% (28/50) of the MRSA isolates were positive for the mec A gene. The existence of the mecA gene among farm workers and broilers MRSA isolates was statistically significant different $(\mathrm{p}=0.008)$. Amongst the farm workers MRSA, 85.7\% (12/14) isolates were mecApositive. While, $44.4 \%(16 / 36)$ of the broiler's MRSA isolates were mecA-positive.

Table 3: Antimicrobial resistance patterns of the MRSA isolates from farm workers and broilers in different farms

\begin{tabular}{lccccccccccc}
\hline \multirow{2}{*}{ Farms } & \multirow{2}{*}{ Source } & \multirow{2}{*}{ S. } & OXA & VAN & CHL & CIP & Dox & AMK & MEM & ERY & TIL \\
& & aureus & R (\%) & R (\%) & R $(\%)$ & R (\%) & R (\%) & R (\%) & R (\%) & R (\%) & R (\%) \\
\hline \multirow{2}{*}{ Akre } & $\mathrm{W}$ & 21 & $1(5)$ & $0(0)$ & $0(0)$ & $1(100)$ & $0(0)$ & $0(0)$ & $0(0)$ & $0(0)$ & $0(0)$ \\
& $\mathrm{B}$ & 42 & $6(14)$ & $0(0)$ & $4(67)$ & $6(100)$ & $0(0)$ & $0(0)$ & $1(16)$ & $4(67)$ & $3(50)$ \\
\multirow{2}{*}{ Amediya } & $\mathrm{W}$ & 7 & $1(14)$ & $0(0)$ & $0(0)$ & $0(0)$ & $1(100)$ & $1(100)$ & $0(0)$ & $0(0)$ & $0(0)$ \\
& $\mathrm{B}$ & 49 & $19(38)$ & $1(5)$ & $17(90)$ & $17(90)$ & $15(79)$ & $9(47)$ & $12(62)$ & $4(21)$ & $9(47)$ \\
\multirow{3}{*}{ Bardarsh } & $\mathrm{W}$ & 8 & $6(75)$ & $0(0)$ & $6(100)$ & $3(50)$ & $0(0)$ & $0(0)$ & $1(16)$ & $1(16)$ & $1(16)$ \\
& $\mathrm{B}$ & 18 & $3(17)$ & $0(0)$ & $1(33)$ & $3(100)$ & $0(0)$ & $0(0)$ & $0(0)$ & $2(66)$ & $1(33)$ \\
\multirow{2}{*}{ Shekan } & $\mathrm{W}$ & 15 & $7(46)$ & $0(0)$ & $4(58)$ & $0(0)$ & $5(71)$ & $3(42)$ & $2(28)$ & $0(0)$ & $1(14)$ \\
& $\mathrm{B}$ & 45 & $25(56)$ & $1(4)$ & $25(100)$ & $13(70)$ & $14(43)$ & $16(88)$ & $22(100)$ & $4(23)$ & $4(18)$ \\
\multirow{2}{*}{ Zakho } & $\mathrm{W}$ & 12 & $3(25)$ & $0(0)$ & $1(33)$ & $1(33)$ & $1(33)$ & $0(0)$ & $0(0)$ & $0(0)$ & $0(0)$ \\
& $\mathrm{B}$ & 42 & $10(23)$ & $0(0)$ & $4(40)$ & $1(10)$ & $2(25)$ & $0(0)$ & $1(10)$ & $0(0)$ & $4(40)$ \\
\hline \multirow{2}{*}{ Total } & $\mathrm{W}$ & 63 & $18(28.6)$ & $1(5.5)$ & $15(83)$ & $5(28)$ & $7(39)$ & $4(22)$ & $2(11)$ & $15.5)$ & $2(11)$ \\
& $\mathrm{B}$ & 196 & $63(32.1)$ & $2(3)$ & $51(81)$ & $40(63)$ & $31(49)$ & $27(43)$ & $36(57)$ & $14(22)$ & $21(33)$ \\
\hline$P$ value & & & 0.594 & 0.711 & 0.726 & 0.023 & 0.358 & 0.114 & 0.003 & 0.100 & 0.067 \\
\hline
\end{tabular}

* $\mathrm{W}=$ Workers, $\mathrm{B}=$ Broilers. 


\section{Discussion}

Staphylococci spp. can cause different patterns of infections in farm workers and broilers. About $20 \%$ of the population are almost permanently colonized and $60 \%$ are intermittent carriers, whereas $20 \%$ has never carried $S$. aureus (10). In the current study, similar rate of $S$. aureus occurrence was found in broilers and farm workers $(84.8 \%$ and $84 \%$ respectively). However, among broilers, there were significant differences of the prevalence of $S$. aureus in different farms. Also, there was significant difference in carriage rate of $S$. aureus among farm workers in different farms. Studies showed different rates of $S$. aureus in different regions $(11,12)$. Our study showed higher rate compared to a study performed in Mosul-Iraq by Shareef $e t$ al., (13), who reported an incidence rate of $S$. aureus in poultry, ranging from 62.5 to $79.16 \%$. Also, Bakeet and Darwish (14) reported the rate $72.5 \%$ of $S$. aureus isolates from chickens samples in Egypt. However, the $S$. aureus rate in our study was lower than the rate that detected by Thompson et al., (15) who reported a high rate $(97.9 \%)$ of $S$. aureus occurrence among chickens.

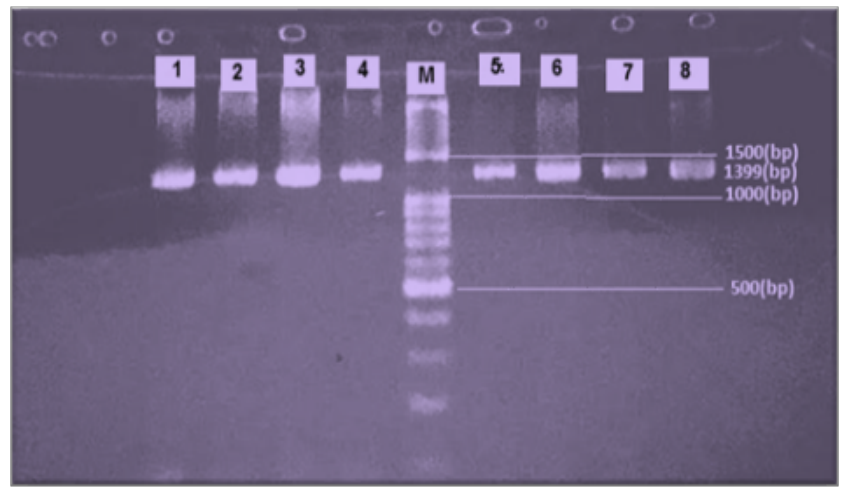

Figure 1: The amplified PCR-products for the mecA gene from MRSA isolates using MR1 and MR2 primers. M: DNA ladder. Lanes 1,2,3, and 4 represent MRSA isolates from farm workers. Lanes 5,6,7, and 8 MRSA isolates from broilers.

The prevalence of $S$. aureus nasal carriage among healthy adults is highly variable, with strong associations with high farm workers population density (16). Studies showed that the carriage rates of $S$. aureus among university students, secondary school student, and healthcare staff were $17.5 \%, 18.4 \%$ and $22.5 \%$, respectively (17-19). The high prevalence of $S$. aureus among farm workers in present study may be due to the regular direct contact with large number of poultry on each farm (ranging between 20000 broilers per farm). Also, the high prevalence of $S$. aureus among farm workers could be due to carrying and handling broilers for treatment purpose and inadequate cleaning of farm facilities contaminated with chicken feces. In an epidemiological study reported the presence of $S$. aureus in $50 \%$ of dust samples obtained from poultry farms environments (20). Contamination of the farm worker's food or water supplies with chicken fecal or food residues may be one route by which MRSA transmission from these animals to farm workers groups may be taking place (21).

Amongst farm workers groups, MRSA carrier was 24\%, while in broilers it was $27.3 \%$. Moreover, the incidence rate of MRSA isolates among broilers in different farms was significant. Also, it was significant among farm workers in different farms. Studies showed various rates of the distribution of MRSA among farm workers and chickens $(22,23)$. MRSA prevalence rates were lower than that reported by Richter et al., (24) which found that the prevalence rate of MRSA was $(71.5 \%)$ and Suk-kyung et al. (25) was (43.3\%). Furthermore, the MRSA-positive broilers rate in this study was higher than the finding of other studies which showed a low prevalence of MRSA among broilers $(22,24,26,27)$. In contrast, Geenen et al. (28) found that MRSA strains amongst people living and/or working in these farms and chickens were only $5.5 \%$ and $8 \%$ respectively.

The high prevalence of MRSA among farm workers groups may be attributed to prolonged physical contact of people and broilers (especially when farm workers treat, vaccinate, and clean livestock) (29). The prevalence of MRSA among broilers is probably due to the high and unrestricted uses of antimicrobial drugs on large farms. The use of most antimicrobial agents on poultry farms, food supplements, and prophylaxis has been reported to be a hazard and risk factor for the prevalence and spread of MRSA infection (30). Antimicrobial drug misuse therefore is a major factor for the spread of MRSA from domesticated animals to farm workers.

In the current study, $32.1 \%$ of broilers MRSA isolates and $28.6 \%$ of farm workers MRSA isolates were resistant to oxacillin. Results from other studies showed varied resistance of MRSA isolates towards different antibiotics $(31,32)$. Our results partially come in accordance with Mulders et al., (33) findings who recorded that the antibiotic resistance was $30 \%$ for erythromycin and $42 \%$ for ciprofloxacin. However, Neela et al. (22) recorded that all isolates were resistant to ciprofloxacin.

In the current study one MRSA isolate from farm workers $(5.5 \%)$ and two from broilers $(3 \%)$ were resistance toward vancomycin. Several studies showed that MRSA isolates were resistant to vancomycin $(34,35)$. While other investigations showed that all MRSA isolates were susceptible to vancomycin $(22,36)$. The high resistant to vancomycin in poultry may be due the use of macrolide antibiotics such as tylosin as growth promoter and prophylaxes which can be linked to vancomycin-resistance 
genes $(\operatorname{van} \mathrm{A})$. The relationship of vancomycin resistance to macrolide resistance has also been detected in farm workers groups (37). Vancomycin is regarded to be a drug of choice for farm workers MRSA infections, but it is possible that the occurrence and spread of new vancomycin-resistant strains from animal source might therefore possibly have very serious consequences for the treatment of MRSA infections in farm workers groups. In addition, although some antibiotics are only used in veterinary medicine, such as tilmicosin, may spread vancomycin resistant MRSA to groups. Furhtermore, presence of high levels of antibiotic resistance in $S$. aureus and MRSA in chickens destined for the food supply chain are worrying because such strains could be passed to farm workers through the consumption of poultry (38).

Recognition of the mecA gene is regarded as the gold standard for the diagnosis of MRSA isolates (39). However, studies showed varied rates of the mecA gene existing among MRSA isolates from poultry farm workers and among healthy individuals (i.e. CA- MRSA) $(19,36)$.

It is found that amongst the tested farm workers MRSA isolates, $85.7 \%$ were mecA-positive. While, $44.4 \%$ of the tested broilers MRSA isolates were mecA-positive. The lack of the mecA gene within MRSA isolates in both farm workers and broilers have been widely reported. The current result is similar to observations by Lee (41) who reported that only $53 \%$ MRSA isolates were mecA positive in broilers. However, our results was higher than Mulders et al., (38) who found only $28 \%$ poultry MRSA were carrying the mecA gene. A study from Egypt on broiler chickens MRSA infections prevalence revealed that all isolates were carrying the mecA gene (14). But, in a study in Jordan, $71 \%$ of MRSA isolated from chickens found to be mecA positive (34). Additionally, Nemati et al. (40) reported that $81 \%$ of chickens $S$. aureus isolates carried the mecA gene.

The absence of the mecA gene within resistant MRSA isolates may be due to hyper-production of $\beta$-lactamase by the bacteria (41), or due to particular modifications in different amino acids existing in penicillin binding proteins cascade (PBPs 1-3), which may be the origin of resistance (42). These support the idea that there are specific mechanisms or alternative genes rather than the existence of the mecA gene which contributes for beta-lactam resistance of MRSA.

\section{Conclusion}

High prevalence of $S$. aureus and MRSA were observed in both farm workers and chickens. All MRSA isolates in farm workers and broiler chickens were highly resistant to chloramphenicol. Resistant to vancomycin antibiotics was observed. All MRSA isolates from both farm workers and broilers showed multi-drug resistant patterns. Additionally, not all MRSA strains possessed the mecA gene. Hence, this should be taken into consideration by regional and reference laboratories. Further investigations are needed to analysis the molecular epidemiological relatedness of MRSA isolates from farm workers and poultry.

\section{Acknowledgements}

We thank all farm workers and farm owners for their collaboration during sample collection. Also, we would like to thank veterinary department, Dohuk governorate for providing the approval to access the farms.

\section{References}

1. Wertheim HF, Melles DC, Vos MC, van Leeuwen W, van Belkum A, Verbrugh HA, Nouwen JL. The role of nasal carriage in Staphylococcus aureus infections. Lancet Infect Dis. 2005;5(12):751762. DOI: 10.1016/S1473-3099(05)70295-4.

2. Kirby WM. Extraction of a highly potent penicillin inactivator from penicillin resistant Staphylococci. Science. 1944;99(2579):452-453. DOI: $10.1126 /$ science. 99.2579 .452 .

3. Jevons MP. Celbenin-resistant staphylococci. Bangladesh Med J. 1961;1:124-125.

4. Nemati M, Hermans K, Lipinska U, Denis O, Deplano A, Struelens M, Devriese LA, Pasmans F, Haesebrouck F. Antimicrobial resistance of old and recent Staphylococcus aureus isolates from poultry: first detection of livestock-associated methicillin-resistant strain ST398. Antimicrob Agents Chemother. 2008;52(10):3817-3819. DOI: 10.1128/AAC.00613-08

5. Murra M, Mortensen KL, Wang M. Livestock-associated methicillinresistant Staphylococcus aureus (clonal complex 398) causing bacteremia and epidural abscess. Int J Infect Dis. 2019;81:107-109. DOI: 10.1016/j.ijid.2019.01.012.

6. Kevorkijan BK, Petrovic Z, Kocuvan A, Rupnik M. MRSA diversity and the emergence of LA-MRSA in a large teaching hospital in Slovenia. Acta Microbiol Immunol Hung. 2019:1-12. DOI: 10.1556/030.65.2018.052.

7. Lowder BV, Guinane CM, Ben Zakour NL, Weinert LA, ConwayMorris A, Cartwright RA, Simpson AJ, Rambaut A, Nubel U, Fitzgerald JR. Recent human-to-poultry host jump, adaptation, and pandemic spread of Staphylococcus aureus. Proc Natl Acad Sci U S A. 2009;106(46):19545-19550. DOI: 10.1073/pnas.0909285106.

8. Dweba CC, Zishiri OT, El Zowalaty ME. Methicillin-resistant Staphylococcus aureus: livestock-associated, antimicrobial, and heavy metal resistance. Infect Drug Resist. 2018;11:2497-2509. DOI: 10.2147/IDR.S175967.

9. Schulz J, Boklund A, Toft N, Tariq H. Effects of control measures on the spread of LA-MRSA among Danish pig herds between 2006 and 2015 - a simulation study. Scic Rep. 2019;9(1):691. DOI: 10.1038/s41598-018-37075-8.

10. Latour K, Huang TD, Jans B, Berhin C, Bogaerts P, Noel A, Nonhoff C, Dodemont M, Denis O, Ieven M, Loens K, Schoevaerdts D, Catry $\mathrm{B}$, Glupczynski Y. Prevalence of multidrug-resistant organisms in nursing homes in Belgium in 2015. PLoS One. 2019;14(3):e0214327. DOI: 10.1371/journal.pone.0214327.

11. Conlon GM, Aldeyab M, Scott M Kearney MP, Farren D, Gilmore F, McElnay J. Effects of antibiotic cycling policy on incidence of healthcare-associated MRSA and Clostridioides difficile infection in secondary healthcare settings. Emerg Infect Dis. 2019;25(1):52-62. DOI: $10.3201 /$ eid2501.180111.

12. CLSI. Clinical and laboratory standards institute. Performance standards for antimicrobial susceptibility testing; Twenty-Fifth informational supplement. CLSI-NCCLS document M100-S25. Clinical and laboratory standards institute, Wayne, PA. 2015. 
13. Tokue Y, Shoji S, Satoh K, Satoh K, Watanabe A, Motomiya M. Comparison of a polymerase chain reaction assay and a conventional microbiologic method for detection of methicillin-resistant Staphylococcus aureus. Antimicrob Agents Chemother. 1992;36(1):69. DOI: 10.1128/aac.36.1.6.

14. Hussein NR, Basharat Z, Muhammed AH, Al-Dabbagh SA. Comparative evaluation of MRSA nasal colonization epidemiology in the urban and rural secondary school community of Kurdistan, Iraq. PLoS One. 2015;10(5):e0124920.DOI: 10.1371/journal.pone.0124920.

15. Murakami K, Minamide W, Wada K, Nakamura E, Teraoka H, Watanabe S. Identification of methicillin-resistant strains of staphylococci by polymerase chain reaction. J Clin Microbiol. 1991;29:2240-2244.

16. Krupa P, Bystron J, Bania J, Podkowik M, Empel J, Mroczkowska A. Genotypes and oxacillin resistance of Staphylococcus aureus from chicken and chicken meat in Poland. Poult Sci. 2014;93(12):31793186. DOI: $10.3382 / p s .2014-04321$.

17. Hanson BM, Dressler AE, Harper AL, Scheibel RP, Wardyn SE, Roberts LK, Kroeger JS, Smith TC. Prevalence of Staphylococcus aureus and methicillin-resistant Staphylococcus aureus (MRSA) on retail meat in Iowa. J Infect Public Health. 2011;4(4):169-174. DOI: 10.1016/j.jiph.2011.06.001.

18. Shareef AM, Mansour RS, Ibrahim KK. Staphylococcus aureus in commercial breeder layer flocks. Iraqi J Vet Sci. 2009;23(I):63-68.

19. Bakeet AAM, Darwish SF. Phenotypic and genotypic detection of methicillin- resistant Staphylococcus aureus (MRSA) in broiler chickens. Assiut Vet Med J. 2014;60(143):142-151.

20. Thompson JK, Gibbs PA, Patterson JT. Staphylococcus aureus in commercial laying flocks: incidence and characteristics of strains isolated from chicks, pullets and hens in an integrated commercial enterprise. $\quad \mathrm{Br}$ Poult Sci. 1980;21(4):315-330. DOI: 10.1080/00071668008416675.

21. Hussein NR, Alyas A, Majeed M, Assafi MS. Prevalence rate and prevalent genotypes of CA-MRSA in Kurdistan region: First report from Iraq. Int J Pure Appl Sci Technol. 2015;27(1):44-49. DOI: 10.17795/iji-35375.

22. Habeeb A, Hussein NR, Assafi MS, Al-Dabbagh SA. Methicillin resistant Staphylococcus aureus nasal colonization among secondary school students at Duhok city - Iraq. J Microbiol Infect Dis. 2014;4(2):59-63. DOI: 10.5799/ahinjs.02.2014.02.0128. DOI: 10.5799/ahinjs.02.2014.02.0128.

23. Hussein NR, Muhammed AH, Al-Dabbagh S, Abdulkareem WL, Assafi MS. The Prevalence of USA300 CA-MRSA in Kurdistan region, northern Iraq. Int J Pure Appl Sci Technol. 2014;21(2):8-10.

24. Hussein NR, Assafi MS, Ijaz T. Methicillin-resistant Staphylococcus aureus nasal colonization amongst healthcare workers in Kurdistan Region, Iraq. J Glob Antimicrob Resist. 2017;9:78-81. DOI: 10.1016/j.jgar.2017.01.010.

25. Soliman SE, Reddy PG, Mohamed Sobeih AA, Busby H, Rowe ES. Epidemiological surveillance on environmental contaminants in poultry farms. Inter J Poul Sci. 2009;8(2):151-155. DOI: 10.3923/ijps.2009.151.155.

26. Adegunloye DV. Microorganisms associated with poultry faeces. J Food Agricul Environ. 2006;4:41-42.

27. Neela V, Ghaznavi E, Ghasemzadeh-Moghaddam, Shamsudin MN, van Belkum A, Karunanidhi A. Frequency of methicillin resistant Staphylococcus aureus in the noses of Malaysian chicken farmers and their chicken. Iranian J Vet Res. 2013;14(3):226-231. DOI: 10.22099/ijvr.2013.1685.

28. Assafi MS, Polse RF, Hussein NR, Haji AH, Issa AR. The Prevalence of $S$. aureus Nasal colonization and its Antibiotic Sensitivity Pattern amongst Primary School Pupils. SJUOZ. 2017;5(1):7-10. DOI: 10.25271/2017.5.1.291.

29. Richter A, Sting R, Popp C, Rau J, Tenhagen BA, Guerra B, Hafez HM, Fetsch A. Prevalence of types of methicillin-resistant Staphylococcus aureus in turkey flocks and personnel attending the animals. Epidemiol Infect. 2012;140(12):2223-2232. DOI: 10.1017/S095026881200009X.

30. Suk S, Nam L, Park H, Lee H, Choi H, Jung M, Santos SI, Mato R, de Lencastre H, Tomasz AS, Lee J, Kim Y, Sang S, Wee S. Prevalencea and characterization of methicillin-resistant Staphylococcus aureus in raw meat in Korea. J Microbiol Biotechnol. 2010;20(4):775-778. DOI: 10.4014/jmb.0912.12022.

31. Bhargava K, Wang X, Donabedian S, Zervos M, de Rocha L, Zhang Y. Methicillin-resistant Staphylococcus aureus in retail meat, Detroit, Michigan, USA. Emerg Infect Dis. 2011;17(6):1135-1137. DOI: 10.3201/eid/1706.101905.

32. Oke AJ, Oke A. Incidence of Methicillin-Resistant Staphylococcus aureus (MRSA) In a Small Poultry in South-West, Nigeria. IOSR J Agricul Vete Sci. 2013;5:53-55. DOI: 10.9790/2380.0535355.

33. Geenen PL, Graat EA, Haenen A, Hengeveld PD, Van Hoek AH, Huijsdens XW, Kappert CC, Lammers GA, Van Duijkeren E, Van De Giessen AW. Prevalence of livestock-associated MRSA on Dutch broiler farms and in people living and/or working on these farms. Epidemiol Infect. 2013;141(5):1099-1108. DOI: $10.1017 / \mathrm{S} 0950268812001616$.

34. Voss A, Loeffen F, Bakker J, Klaassen C, Wulf M. Methicillinresistant Staphylococcus aureus in pig farming. Emerg Infect Dis. 2005;11(12):1965-1966. DOI: 10.3201/eid1112.050428.

35. $\mathrm{Pu} \mathrm{S}$, Han F, Ge B. Isolation and characterization of methicillinresistant Staphylococcus aureus strains from Louisiana retail meats. Appl Environ Microbiol. 2009;75(1):265-267. DOI: 10.1128/AEM.01110-08

36. Waters AE, Contente-Cuomo T, Buchhagen J, Liu CM, Watson L, Pearce K, Foster JT, Bowers J, Driebe EM, Engelthaler DM, Keim PS, Price LB. Multidrug-resistant Staphylococcus aureus in US meat and poultry. Clin Infec Dis. 2011;52(10):1227-1230 DOI: $10.1093 / \mathrm{cid} / \mathrm{cir} 181$.

37. Rinsky JL, Nadimpalli M, Wing S, Hall D, Baron D, Price LB, Larsen J, Stegger M, Stewart J, Heaney CD. Livestock-associated methicillin and multidrug resistant Staphylococcus aureus is present among industrial, not antibiotic-free livestock operation workers in north Carolina. PLoS ONE. 2013;8(7):e67641. DOI: 10.1371/journal.pone.0067641.

38. Mulders MN, Haenen AP, Geenen PL, Vesseur PC, Poldervaart ES, Bosch T, Huijsdens XW, Hengeveld PD, Dam-Deisz WD, Graat EA, Mevius D, Voss A, Van De Giessen AW. Prevalence of livestockassociated MRSA in broiler flocks and risk factors for slaughterhouse personnel in the Netherlands. Epidemiol Infect. 2010;138(5):743-755. DOI: $10.1017 / \mathrm{S} 0950268810000075$.

39. Quddoumi SS, Bdour SM, Mahasneh AM. Isolation and characterization of methicillin-resistant Staphylococcus aureus from livestock and poultry meat. Annals Microbiol. 2006;56(2):155-161. DOI: 10.1007/BF03174998.

40. Otalu OJ, Kabir J, Okolocha EC, Umoh VJ. Multi-drug resistant coagulase positive Staphylococcus aureus from live and slaughtered chickens in Zaria, Nigeria. Internat J Poul Sci. 2011;10(11):871-875 DOI: 10.3923/ijps.2011.871.875.

41. Lee JH. Occurrence of methicillin-resistant Staphylococcus aureus strains from cattle and chicken, and analyses of their mecA, mecRI and mecI genes. Vet Microbiol. 2006;114:155-159. DOI: 10.1016/j.vetmic.2005.10.024.

42. Uttley AH, George RC, Naidoo J, Woodford N, Johnson AP, Collins $\mathrm{CH}$, Morrison D, Gilfillan AJ, Fitch LE, Heptonstall J. High-level vancomycin-resistant enterococci causing hospital infections. Epidemiol Infect. 1989;103(1):173-181. DOI: $10.1017 / \mathrm{s} 0950268800030478$.

43. Papadopoulou C, Dimitriou D, Levidiotou S, Gessouli H, Panagiou A, Golegou S, Antoniades G. Bacterial strains isolated from eggs and their resistance to currently used antibiotics: is there a health hazard for consumers? Comp Immunol Microbiol Infect Dis. 1997;20(1):3540. DOI: $10.1016 / \mathrm{S} 0147-9571(96) 00024-0$. 
44. Elhassan MM, Ozbak HA, Hemeg HA, Elmekki MA, Ahmed LM. Absence of the mecA gene in methicillin resistant Staphylococcus aureus isolated from different clinical specimens in Shendi city, Sudan. Biomed Res Int. 2015;2015:895860. DOI: $10.1155 / 2015 / 895860$.

45. Olayinka BO, Olayinka AT, Obajuluwa AF, Onaolapo JA, Olurinola $\mathrm{PF}$. Absence of mecA gene in methicillin-resistant Staphylococcus aureus isolates. Afr J Infect Dis. 2009;3(2):49-56. DOI: 10.4314/ajid.v3i2.55081.

46. Ba X, Harrison EM, Edwards GF, Holden MTG, Larsen AR, Petersen A, Skov RL, Peacock SJ, Parkhill J, Paterson GK, Holmes MA. Novel mutations in penicillin-binding protein genes in clinical Staphylococcus aureus isolates that are methicillin resistant on susceptibility testing, but lack the mecA gene. J Antimicrob Chemother. 2014;69(3):594-597. DOI: 10.1093/jac/dkt418. 